\title{
Asymptomatic neonatal colonisation by Clostridium difficile
}

\author{
R P BOLTON, S K TAIT, P R F DEAR, AND M S LOSOWSKY
}

University Departments of Medicine, Obstetrics, and Paediatrics, St James's University Hospital, Leeds

SUMMARY In a prospective survey of infants born in a single maternity unit, asymptomatic faecal colonisation by Clostridium difficile occurred in $31(47 \%)$ of 66 babies who provided a faecal sample during week one of life and at age 14 and 28 days, and in $46(30.7 \%)$ of the total of 150 babies for whom at least one faecal sample was obtained during the month of study. There was no evidence for acquisition of the organism from the mother during delivery and colonisation was unrelated to the means of delivery, infant sex, means of feeding, duration of hospital stay, or antibiotic treatment. New colonisation occurred throughout the month of the study and further evidence for environmental acquisition was obtained by the finding of a similar strain of $C$ difficile in 7 babies from one ward together with positive environmental cultures. Colonisation was frequently transient and occasionally intermittent; most infants kept the same strain during their period of carriage. Twenty two $(47 \cdot 8 \%)$ babies colonised by $C$ difficile had low titres of cytopathic faecal toxin but none had symptomatic diarrhoea or features of necrotizing enterocolitis. The in vitro toxigenic potential of 57 toxigenic isolates from 36 babies was low and 12 babies carried non-toxigenic strains.

Transient colonisation by $C$ difficile in early life is almost certainly more common than is generally recognised and the neonate provides an important reservoir of potential infection.

Clostridium difficile is now generally accepted as the major aetiological agent in most adults with antibiotic associated pseudomembranous colitis and in a variable percentage of patients with antibiotic associated diarrhoea. ${ }^{1}$ Faecal carriage of $C$ difficile in healthy adults is around two per cent ${ }^{2}$ but although this may rise during antibiotic treatment, ${ }^{3}$ the presence of faecal cytopathic toxin as detected by tissue culture assay is generally limited to those patients with diarrhoea. ${ }^{34}$ In neonates, however, asymptomatic faecal carriage of $C$ difficile, ${ }^{5}$ often with positive cytotoxin, occurs in up to $40 \% .^{367}$ Whether this reflects a different susceptibility of the infant gut to the effects of the organism or a reduced pathogenicity of the organism itself is uncertain but it does seem that neonates provide an important reservoir for the organism. Most previous studies have reported results of single or infrequent specimens and the source of acquisition of $C$ difficile and its natural history during the neonatal period are currently uncertain. The present prospective study was designed to follow all the babies born in a single maternity unit and to examine the questions of maternal or environmental acquisition together with a study of the natural history of $C$ difficile in the neonatal period.

\section{Patients and methods}

Patients. All 174 women admitted in labour to a single maternity unit during an 18 day period in November 1981 were included in the study but in 13 no information was subsequently available and we therefore report the findings in the remaining 161 patients and their offspring.

Maternal rectal and vaginal swabs taken during early labour were put in Amies Charcoal Medium (Transwab, Medical Wire and Equipment, UK); specimens were maintained at $4^{\circ} \mathrm{C}$ and processed within 15 hours of collection. Both samples were available in 126 patients, a rectal swab only was available in 11 , a vaginal swab only in two, and neither swab was available in the remaining 22 subjects.

One hundred and sixty three babies were born to the 161 mothers; there were two sets of twins. Neonatal meconium and faecal samples were collected into dry specimen pots (Henley's Medical 
Supplies, UK) on days $1,4,7,14$, and 28 of life where possible and were processed immediately. Outpatient samples were collected by visiting midwives and kept at $4^{\circ} \mathrm{C}$ where possible. All five faecal specimens were obtained from 35 babies, four specimens from 42 , three from 27 , two from 26 , one from 20 , and no faecal specimen was obtained from 13 babies. One hundred and fourteen samples were available from day 1,99 from day 4,101 from day 7 , 100 from day 14 , and 82 from day 28 giving a total of 496 faecal samples.

Wards. After delivery patients were nursed in three postnatal wards; wards 2 and 3 were joined by a common entrance while ward 4 was geographically separate but on the same floor. Although each ward was self contained and had its own nursing staff, wards 2 and 3 shared a common kitchen at the entrance to ward 3. Babies were nursed by the mother's bed in the open ward during the day and often shared a common nursery at night. Two preterm infants were nursed in the special care unit which was self contained and on a separate floor.

Environmental swab cultures (Amies Charcoal Medium) were taken from the sluice, nursery, and ward areas of each ward at weekly intervals from the start of the study and were processed within one hour of collection.

Culture. Maternal and environmental swabs and neonatal faecal samples were plated on to a commercially available semiselective medium containing cefoxitin and cycloserine (Oxoid, UK) and were incubated anaerobically at $37^{\circ} \mathrm{C}$ for 48 to 72 hours in resealable jars (Becton Dickinson, UK) using gas generating kits.

All swabs and faecal samples were also incubated at $37^{\circ} \mathrm{C}$ in Shaedler meat broth (Oxoid, UK) containing $0 \cdot 2 \%$ p-cresol (BDH Chemicals, UK) and subcultured on blood agar after 7 and 28 days incubation. Likely colonies of $C$ difficile were subcultured on blood agar and identified by standard morphological and biochemical parameters and by gas liquid chromatography. ${ }^{8}$

Cytopathic toxin assay. All toxin assays were performed using HEp2 cell monolayers (Flow Laboratories, UK) in microtitre plates (Flow Laboratories, UK), $50 \mu \mathrm{l}$ of test suspension being added to $200 \mu \mathrm{l}$ of medium in each well. After incubation at $37^{\circ} \mathrm{C}$ for 24 hours a positive cytopathic response was seen as a rounding up and detachment of cells from the monolayer, preventable by the prior addition of $50 \mu \mathrm{l}$ of a 1 in 100 dilution of Clostridium sordellii antiserum (Wellcome Foundation, UK) to $150 \mu \mathrm{l}$ of tissue culture medium in each test well. ${ }^{9}$
Titration of the cytopathic toxin was performed using doubling dilutions from a starting dilution of 1 in 10 of test suspension in sterile phosphate buffered saline. The end point was recorded as the well showing at least $50 \%$ of cells affected and was expressed as the logarithm $\mathrm{m}_{10}$ reciprocal of the final dilution.

\section{Faecal supernatants}

These were prepared from a 1 in 5 dilution of faeces in sterile phosphate buffered saline after centrifugation at $4000 \mathrm{rpm}$ for 20 minutes and were stored at $-20^{\circ} \mathrm{C}$ until tested in the cytopathic toxin assay. All samples were assayed within 14 days of collection.

\section{Toxigenic potential of $C$ difficile in vitro}

This was taken as the cytopathic toxin titre $\left(\log _{10}\right)$ of the supernatant taken after five days incubation of a pure culture in cooked meat broth (equal volumes of thiol broth (Difco, UK) and a solution containing $3 \%$ tryptone (Difco, UK) and $0.5 \%$ yeast extract (Difco, UK) in distilled water, with $1.5 \mathrm{~g}$ of meat granules (Lab M, UK) per $20 \mathrm{ml}$ of final broth) ${ }^{3}$ and tested without prior storage.

\section{Antibiotic sensitivity profiles}

Antibiotic sensitivity profiles were obtained by the disc diffusion method using $6 \mathrm{~mm}$ impregnated discs (Mast Laboratories, UK) incorporating clindamycin $(2 \mu \mathrm{g})$, tetracycline $(25 \mu \mathrm{g})$, benzyl-penicillin (1 IU), cefuroxine $(30 \mu \mathrm{g})$, erthyromycin $(5 \mu \mathrm{g})$, or neomycin $(10 \mu \mathrm{g})$ on blood agar plates flooded with a 24 hour pure broth culture of the isolate under test. Each isolate was labelled resistant (R) if the diameter of the zone of growth inhibition was less than $10 \mathrm{~mm}$. Strains were said to show intermediate resistance (I) if the zone of inhibition was between 10 and $20 \mathrm{~mm}$, and to be fully sensitive (S) if the zone was greater than $20 \mathrm{~mm}$.

Statistical analysis was performed using Student's $t$ test or Fisher's exact test as appropriate.

\section{Results}

Maternal specimens. $C$ difficile could not be cultured from any of the 128 maternal vaginal swabs and was isolated in only one of 137 maternal rectal swab cultures. In this patient $C$ difficile was isolated only in broth culture after 28 days incubation, vaginal culture was negative, and all five neonatal faecal specimens were negative on culture and in the toxin assay.

Neonatal specimens. Seventy five $(15 \%)$ of the 496 neonatal faecal samples received contained either 
Table 1 Detection of $C$ difficile and cytotoxin in 496 faecal samples from 150 babies during the first month of life

\begin{tabular}{|c|c|c|c|c|c|c|c|}
\hline \multirow[t]{2}{*}{ Day } & \multirow{2}{*}{$\begin{array}{l}\text { Samples } \\
\text { tested }\end{array}$} & \multicolumn{4}{|c|}{$C^{*}$ difficile positive } & \multirow{2}{*}{$\begin{array}{l}\text { No of known } \\
\text { carriers tested } \\
\text { (max 46) }\end{array}$} & \multirow{2}{*}{$\begin{array}{l}\text { Percentage of } \\
\text { carriers positive }\end{array}$} \\
\hline & & $\begin{array}{l}\text { Total } \\
\text { No }(\%)\end{array}$ & $\begin{array}{l}\text { Organism } \\
\text { only }\end{array}$ & $\begin{array}{l}\text { Organism } \\
\text { and toxin }\end{array}$ & $\begin{array}{l}\text { Toxin } \\
\text { only }\end{array}$ & & \\
\hline 1 & 114 & $3(2 \cdot 6)$ & 1 & - & 2 & 31 & $9 \cdot 7$ \\
\hline 4 & 99 & $13(1.3)$ & 9 & 3 & 1 & 36 & 36 \\
\hline 7 & 101 & $7(6.9)$ & 4 & 3 & - & 37 & 18.9 \\
\hline 14 & 100 & $24(24)$ & 12 & 12 & - & 41 & $58 \cdot 5$ \\
\hline 28 & 82 & $28(.34)$ & 19 & 8 & 1 & 35 & 80 \\
\hline Total & 496 & 75 & 45 & 26 & 4 & & \\
\hline
\end{tabular}

organism $(n=45)$ or toxin $(n=4)$, or both $(n=26)$ and the number of positive samples obtained on each collection day is shown in Table 1.

Forty six $(30.7 \%)$ of the 150 babies from whom at least one faecal sample was obtained were positive for $C$ difficile or its cytotoxin at some stage during the study and in 22 of $46(47 \cdot 8 \%)$ faecal cytotoxin was found on one $(n=15)$, two $(n=6)$, or three $(n=1)$ occasions. $C$ difficile was isolated in 45 infants but could not be identified in one further baby in whom specifically neutralisable faecal cytotoxin was present on one occasion. Faecal toxin titres were low, mean (SD) $1.43(0 \cdot 38)$ (range 1 to $2 \cdot 2)\left(\log _{10}\right)$, and none of the 46 infants positive for $C$ difficile had

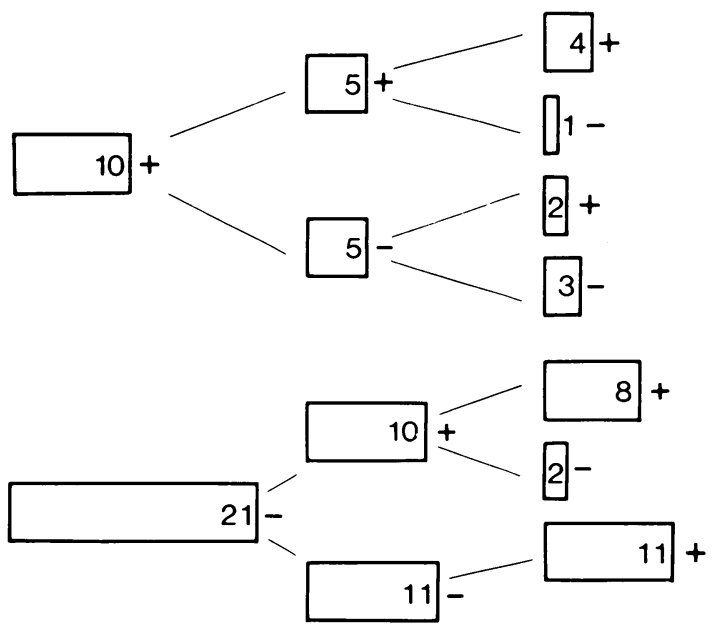

7 days $\quad 14$ days 28 days

Fig. 1 Pattern of faecal colonisation by Clostridium difficile in 31 neonates tested during the first week of life and at 14 and 28 days. (+1- indicates the result of faecal culture/toxin assay). symptomatic diarrhoea or features of necrotizing enterocolitis.

Complete faecal collections (that is, specimens from days $1,4,7,14$, and 28) were available in 35 babies and $C$ difficile was present at some stage in 16 $(46 \%)$ of these. Fifteen $(48 \%)$ of a further 31 babies with at least one faecal sample from the first week together with samples from both 14 and 28 days were found to be positive for $C$ difficile giving an overall carriage rate of $31(47 \%)$ of 66 babies with representative faecal samples from throughout the month. Ten of these 31 babies $(32 \%)$ had acquired the organism within the first week of life while a further $10(32 \%)$ had become organism positive by age 14 days and the remaining $11(36 \%)$ were first positive when tested at age 28 days (Fig. 1).

Faecal carriage of $C$ difficile in these 31 babies was often transient or intermittent; only four of the 10 babies who were culture positive during the first week were positive at age 14 and 28 days while two babies had apparently re-acquired $C$ difficile at 28 days having been negative at 14 days (Fig. 1). When all 46 babies who were positive for $C$ difficile are included, $16(35 \%)$ had acquired the organism within the first week, $18(39 \%)$ were organism positive when tested at age 14 days, and the remaining $12(26 \%)$ were first positive at 28 days (Table 2).

There were no significant differences between infant sex or means of delivery and the overall incidence or the time $C$ difficile was first found (Table 2), and the duration of hospital stay was similar in the positive (mean (SD) 6.7 (4.3) days) and negative $(5 \cdot 8(2.9)$ days) groups $(\mathrm{P}>0 \cdot 1, \mathrm{NS})$. Nor was there any association between the maternal use of antibiotics in the month before delivery and subsequent neonatal carriage of $C$ difficileantibiotics having been used by the mothers of three $(6.5 \%)$ of the 46 positive babies compared with five $(4.8 \%)$ of $104 C$ difficile negative babies. Three infants were known to have received antibiotics during the period of study but none acquired $C$ 
Table 2 Relation between means of delivery, infant sex, and timing of first detection of $C$ difficile in 150 neonates

\begin{tabular}{|c|c|c|c|c|c|c|c|c|c|c|c|}
\hline \multirow{3}{*}{$\begin{array}{l}\text { Means of } \\
\text { delivery }\end{array}$} & \multirow{3}{*}{$\begin{array}{l}\text { Total } \\
\text { studied }\end{array}$} & \multirow{3}{*}{$\begin{array}{l}C \text { difficile } \\
\text { positive } \\
\text { No }(\%)\end{array}$} & \multicolumn{2}{|l|}{ Boys } & \multicolumn{2}{|l|}{ Girls } & \multicolumn{5}{|c|}{$\begin{array}{l}\text { Day on which toxin } \\
\text { first found }\end{array}$} \\
\hline & & & \multirow[t]{2}{*}{ Total } & \multirow{2}{*}{$\begin{array}{l}\text { Positive } \\
\text { No }(\%)\end{array}$} & \multirow[t]{2}{*}{ Total } & \multirow{2}{*}{$\begin{array}{l}\text { Positive } \\
\text { No }(\%)\end{array}$} & & & & & \\
\hline & & & & & & & $I$ & 4 & 7 & 14 & 28 \\
\hline SVD & 96 & $29(30)$ & 58 & $18(31)$ & 38 & $11(29)$ & 2 & 8 & 2 & 11 & 6 \\
\hline LSCS & 16 & $6(37 \cdot 5)$ & 8 & $3(37 \cdot 5)$ & 8 & $3(37 \cdot 5)$ & 1 & 0 & 0 & 3 & 2 \\
\hline KF & 5 & $2(40)$ & 3 & $2(67)$ & 2 & 0 & 0 & 2 & 0 & 0 & 2 \\
\hline LF & 29 & $8(27 \cdot 5)$ & 16 & $4(25)$ & 13 & $4(31)$ & () & 1 & 0 & 4 & 3 \\
\hline BR & 4 & $1(25)$ & 2 & $1(50)$ & 2 & 0 & 0 & 0 & 0 & 0 & 1 \\
\hline Total & 150 & 46 & 87 & $28(32)$ & 63 & $18(28 \cdot 5)$ & 3 & 11 & 2 & 18 & 14 \\
\hline
\end{tabular}

SVD = spontaneous vaginal delivery LSCS = cacsarean section; $\mathrm{KF}=$ Keilland's forceps: $\mathrm{LF}=$ low forceps; $\mathrm{BR}=\mathrm{breech}$.

difficile. The method of infant feeding was unrelated to colonisation by $C$ difficile with an overall positive rate of $21(30.9 \%)$ of 68 breast fed infants compared with $25(30 \cdot 5 \%)$ of 82 bottle fed infants. Low titres of faecal cytopathic toxin were found in $8(38 \%)$ of the 21 breast fed and in $14(56 \%)$ of the 25 bottle fed babies $(\mathrm{P}>0 \cdot 1, \mathrm{NS})$ but no infant had symptomatic diarrhoea or any features of necrotizing enterocolitis.

Eleven $(23.9 \%)$ of the 46 positive babies first acquired $C$ difficile during admission and the organism was present in a further $17(37 \%)$ when first tested after leaving hospital. The remaining 18 $(39.1 \%)$ babies who subsequently became organism or toxin positive had been negative when tested both during their stay and initially after discharge (Fig. 2).

The overall incidence of $C$ difficile colonisation during the first month of life was similar for babies nursed in the various postnatal wards (Table 3), although significantly more babies in ward 3 than in ward 2 acquired the organism during admission (Table 3).

Antibiogram typing of $C$ difficile. The isolates of $C$ difficile cultured from the five babies who were organism positive during their stay in ward 3 all had the same unusual antibiogram when tested against a range of 6 antibiotics (resistant to clindamycin with intermediate resistance to cefuroxine) (Fig. 2) suggesting a single identity; two further babies (cases 058 and 150) who were culture positive when first tested after discharge also carried a strain of $C$ difficile with the same antibiotic sensitivity profile (Fig. 2). One baby (case 055) had this same strain on three occasions and four babies had the same strain on two occasions during the month of follow up. A further two babies (cases 056 and 108) were colonised with this isolate initially but strains with different antibiograms were subsequently cultured at age 28 days (Fig. 2). Isolates of $C$ difficile with the same antibiotic profile were also obtained from environmental swabs of the nursery and sluice of ward 3 on several occasions during the study period but $C$ difficile was not cultured from environmental swabs of the other wards or the delivery suite and none of the babies from the other wards had strains of $C$ difficile with this antibiogram. The antibiograms of the isolates cultured during admission to other wards or isolated subsequently showed considerable variation and are outlined in Fig. 2.

Twenty one $(46 \%)$ of the 46 positive babies had $C$ difficile positive cultures on more than one occasion and in $19(41 \%)$ of these babies the $C$ difficile antibiograms were the same on each occasion. Both the babies (cases 056 and 108) from whom an isolate with a different antibiogram was subsequently obtained had initially acquired $C$ difficile during their stay in ward 3 (Fig. 2).

Toxigenic potential of $\boldsymbol{C}$ difficile. The toxigenic potential of 57 toxin producing isolates from 36 babies was generally low with mean (SD) 2.01 $(0 \cdot 34)$, (range 1.3 to $2 \cdot 8)\left(\log _{10}\right)$. Non-toxigenic strains of $C$ difficile were isolated on 14 occasions from 12 babies. In 8 babies these were the only strains found, in one baby (case 135) toxin (but not

Table 3 Incidence of colonisation by $C$ difficile during hospital admission and after discharge of neonates nursed in various postnatal wards

\begin{tabular}{|c|c|c|c|}
\hline \multirow{2}{*}{$\begin{array}{l}\text { Ward } \\
\text { no }\end{array}$} & \multirow{2}{*}{$\begin{array}{l}\text { Total } \\
\text { babies }\end{array}$} & \multicolumn{2}{|c|}{$C$ difficile positives } \\
\hline & & $\begin{array}{l}\text { Total } \\
\text { No }(\%)\end{array}$ & $\begin{array}{l}\text { During admission } \\
\text { No }(\%)\end{array}$ \\
\hline 2 & 52 & $15(28 \cdot 8)$ & $2(133)$ \\
\hline 3 & 43 & $10(23 \cdot 3)$ & $5(50)^{*}$ \\
\hline 4 & 53 & $19(35 \cdot 8)$ & $3(15 \cdot 8)$ \\
\hline SCU & 2 & $2(100)$ & $1(50)$ \\
\hline Total & 150 & 46 & 11 \\
\hline
\end{tabular}

* $\mathrm{P}<0.05$ cf ward 2 . 


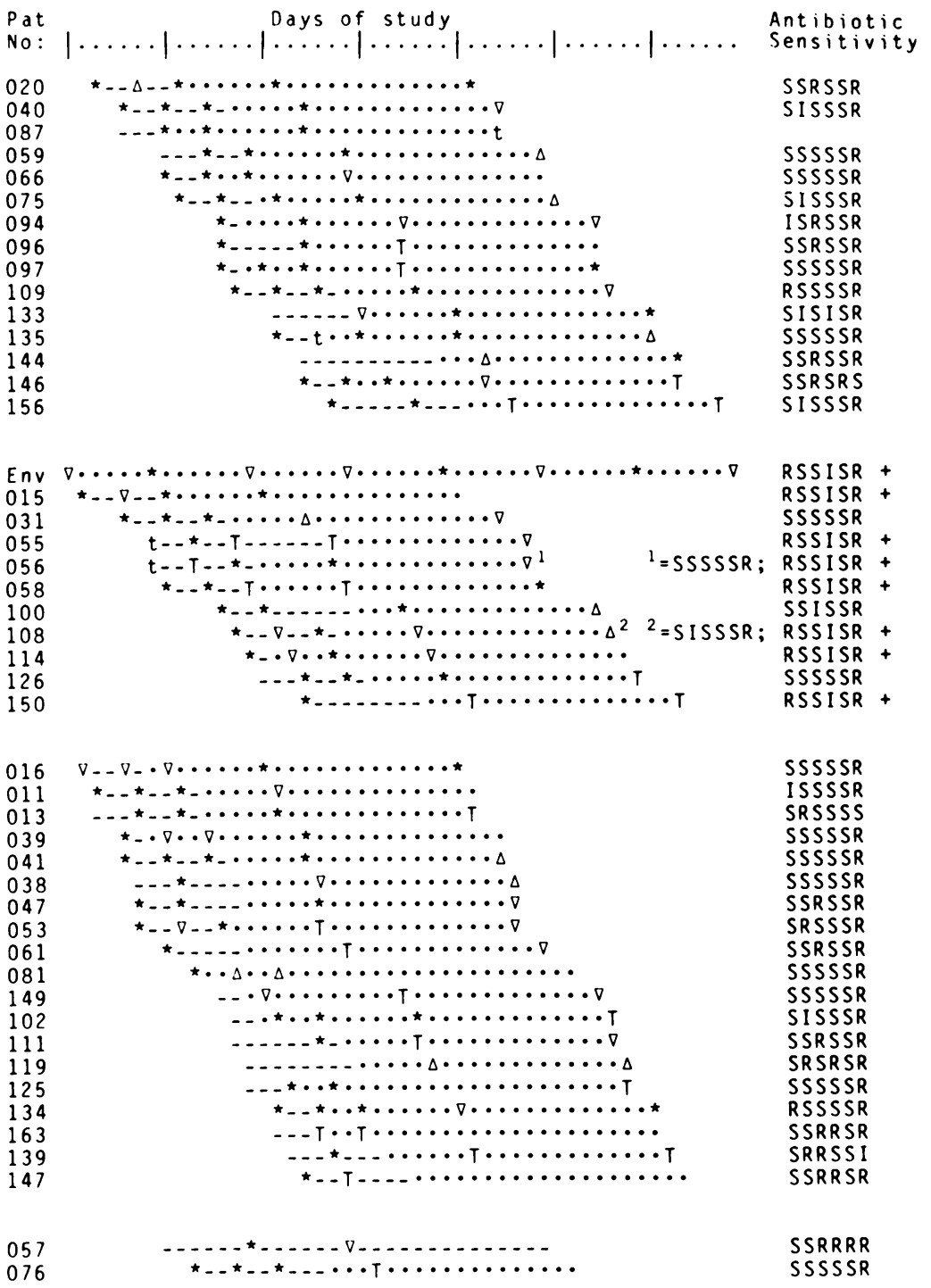

Fig. 2 Natural history of faecal colonisation by Clostridium difficile in 46 neonates found to be either culture or toxin positive or both at some stage during the first month of life.

$\Delta=$ non-toxigenic isolate; $\nabla=$ toxigenic isolate: $\mathrm{T}=$ toxin and organism present; $\mathrm{t}=$ toxin only found; ${ }^{\star}=$ negative specimen; Env $=$ environmental swabs: $---=$ inpatient stay: $\cdots=$ outpatient: $+=$ isolates with the same antibiogram.

Antibiogram profile: clindamycin; tetracyclinc: penicillin; cefuroxime; crythromycin; neomycin. $\mathrm{R}=$ resistant (inhibition zone $<10 \mathrm{~mm}$ ); $\mathrm{I}=$ intermediate (zone $10-20 \mathrm{~mm}$ ); $\mathrm{S}=$ sensitive (zone $>20 \mathrm{~mm}$ ).

organism) had been present previously, and in three babies toxigenic $C$ difficile was previously (cases 038 and 108) or subsequently (case 031 ) found (Fig. 2). Three additional faecal specimens contained cytopathic toxin but $C$ difficile could not be isolated on culture.

\section{Discussion}

The present finding of $C$ difficile in $46(31 \%)$ of 150 asymptomatic, healthy neonates of whom $22(48 \%)$ showed faecal cytopathic toxin confirms previous reports of a high carriage rate of both organism and 
toxin in the neonatal period ${ }^{367}$ and also illustrates the frequently transient and occasionally intermittent nature of colonisation (Fig. 1). Single or infrequent faecal specimen analysis will underestimate the incidence of colonisation, which is likely to be even higher than the present overall finding of $47 \%$ (31 of 66 ) obtained when only those babies with at least one specimen from the first week plus samples at both 14 and 28 days are considered.

Suggestions that $C$ difficile may be acquired by the neonate from the maternal birth canal during delivery, encouraged by the unconfirmed finding of $72 \%$ positive urogenital culture by Hafiz et al, ${ }^{10}$ are not supported by the present study which failed to find $C$ difficile on vaginal culture of 128 mothers and found the organism in only one of 137 maternal rectal swabs, with subsequent negative cultures and toxin assays from the relevant neonate. This is further supported by the similar overall colonisation rate in babies born vaginally $(30 \%)$ or by caesarean section $(38 \%)$, with no increase in colonisation for those requiring instrumentation delivery with forceps (Table 2), although an increase in the incidence of faecal toxin after vaginal delivery has previously been reported. ${ }^{6}$

Colonisation was unrelated to duration of hospital stay, pre- or postnatal antibiotic treatment, or means of infant feeding. The previously reported finding of an increased frequency of faecal toxin in breast fed infants has not been confirmed. ${ }^{6}$

New cases of colonisation by $C$ difficile occurred throughout the month of the study suggesting environmental acquisition, and a similar study of 59 neonates has recently reported an overall colonisation rate approaching $50 \%$ by age 28 days. ${ }^{11}$ The organism is widely dispersed in nature with an asymptomatic reservoir in domestic pets ${ }^{12}$ and in the hospital, environmental contamination and symptomatic cross infection by $C$ difficile have been well described ${ }^{13-15}$ as has culture of the organism from the nursery environment and staff. ${ }^{7} \mathrm{C}$ difficile, a spore forming anaerobe, is able to survive in adverse conditions for many months and it is perhaps surprising that in this study it was cultured from the environment of only one of the three postnatal wards.

Evidence for environmental acquisition with case clustering has previously been reported in a study of 451 newborn infants. Colonisation rates in different wards varied between two and $52 \%$ and on one occasion a potential common source of $C$ difficile was isolated from the environment. ${ }^{16}$ In the present study, using the antibiotic sensitivity profile as a limited means of strain typing, isolates of $C$ difficile with the same, unusual antibiogram (resistance to clindamycin; intermediate resistance to cephradine) were isolated from the environment of ward 3 and subsequently from 7 babies nursed on that wardfive who were organism positive during admission and two who were positive when first tested after leaving hospital-suggesting inpatient acquisition (Fig. 2). A further three babies nursed on ward 3 also became culture positive but with strains showing different antibiograms and all were acquired after leaving hospital (Fig. 2). The environmental strain of $C$ difficile was found to predate its appearance in the neonates under study and was also isolated from the environment on several subsequent occasions up to 6 weeks after completion of the survey suggesting its persistence as a reservoir for infant colonisation. No similar pattern of organism acquisition was found in the other two postnatal wards, the organisms isolated having dissimilar or commonly occurring antibiograms, and although some infants on both wards acquired $C$ difficile during their stay environmental cultures were negative (Fig. 2). Although significantly more babies acquired the organism during their stay on ward 3 than on ward 2, the overall incidence of colonisation during the month of follow up was similar for babies nursed on each of the three wards with a similar, though not significant, trend between wards 3 and 4 (Table 3). Such a pattern is in keeping with environmental acquisition from a wide variety of sources and although two of the infants with the 'ward 3 strain' subsequently acquired strains with different antibiograms (Fig. 2), study of the isolate antibiograms suggests that most infants keep the same strain during their period of colonisation.

None of the babies in this series had any features suggesting necrotizing enterocolitis and the role of $C$ difficile in this condition must remain in doubt. Although Cashore et $a l^{17}$ isolated $C$ difficile toxin from the stools of several symptomatic neonates during a nursery epidemic of necrotizing enterocolitis, others have failed to identify $C$ difficile cytotoxin in these patients ${ }^{1819}$ and another study found toxin in both symptomatic and asymptomatic neonates with no correlation between toxin titre and disease. ${ }^{7}$ In the present study faecal cytopathic toxin titres were generally low (mean (SD) $1.43(0.38) \log _{10}$ ) and well below the values usually found in symptomatic adults using the same assay (unpublished data). Some authors, however, have questioned the relation between toxin titre and disease severity. ${ }^{2021}$ The role of cytotoxin (or toxin B) in the pathogenesis of disease is currently unknown and $C$ difficile produces at least one other toxin, an enterotoxin (toxin A), which causes fluid accumulation in the rabbit ileal loop, ${ }^{22}$ although its role is also uncertain. Numbers of $C$ difficile present in the asymptomatic infant gut are similar to those found in adults with 
symptomatic disease ${ }^{23}$ and although neonatal antibiotic associated pseudomembranous colitis has been recorded, ${ }^{24}{ }^{25}$ it has been suggested that there may be an inherent insusceptibility of the neonatal mucosa to the effects of $C$ difficile.

Reduced pathogenicity of the colonising $C$ difficile has also been suggested to explain the lack of symptoms in the neonate and in the present study 12 $(26 \%)$ of the 46 organism positive babies carried strains that failed to produce toxin in vitro under conditions previously shown to be optimal. These were the only strains found in 8 babies while toxigenic isolates were also found in four babies (Fig. 2). The toxigenic potential of those isolates of $C$ difficile producing toxin in vitro was low (mean (SD) 2.01 $\left.(0.34) \log _{10}\right)$ compared with isolates from symptomatic adults (mean greater than 3.0 ; personal observation) suggesting possible reduced pathogenicity. Viscidi $e t a l^{3}$ have reported no difference, however, between the toxigenic potential of their isolates from neonates and symptomatic adults and as previously stated the pathogenic mechanisms of $C$ difficile induced disease remain unknown.

Although Holst et $a l^{26}$ found $C$ difficile in less than four per cent of their series of 49 neonates, the fact of a high incidence of asymptomatic neonatal colonisation by $C$ difficile now seems generally well established. Its relevance, however, remains uncertain. Most reports agree that after a colonisation incidence of between $40 \%$ and $90 \%$ in infants followed to one year of age $\mathrm{ag}^{2326}$ the finding of faecal $C$ difficile falls rapidly thereafter to a frequency similar to that found in adults, ${ }^{26}$ possibly reflecting the change in the normal enteric flora. Pseudomembranous colitis is rare in childhood $^{28} 29$ and it is possible that colonisation in infancy is desirable, perhaps inducing subsequent protection via some form of mucosal immunity, and this may explain the low incidence of childhood disease and the very variable course of the disease in adults.

We thank Miss Little and all the midwives for their invaluable assistance in specimen collection and transport and Colin Ramsden for expert bacteriological aid.

\section{References}

1 Bartlett JG, Chang TW, Taylor NS, Onderdonk AB. Colitis induced by C. difficile. Rev Infect Dis 1979:1:370-8.

2 Willey S, Bartlett JG. Cultures for C. difficile in stools containing a cytotoxin neutralised by $\mathrm{C}$. sordellii antitoxin. J Clin Microbiol 1979;10:880-4.

3 Viscidi R, Willey S, Bartlett JG. Isolation rates and toxigenic potential of $C$. difficile isolates from various patient populations. Gastroenterology 1981;81:5-9.

${ }^{4}$ Nash JQ, Chattopadhyay B, Honeycombe J, Tabaqchali S. Clostridium difficile and cytotoxin in routine faecal specimens. J Clin Pathol 1982;35:561-5.
${ }^{5}$ Hall IC, O'Toole E. Intestinal flora in newborn infants-with a description of a new pathogenic anaerobe. Bacillus difficilis. Am $J$ Dis Child 1935;49:390-402.

' Donta ST, Myers MG. C. difficile toxin in asymptomatic neonates. J Pediatr 1982;100:431-4.

${ }^{7}$ Sherertz RJ, Sarubbi FA. The prevalence of C. difficile and toxin in a nursery population: a comparison between patients with necrotising enterocolitis and an asymptomatic group. J Pediatr 1982;100:435-9.

${ }^{8}$ Holdeman CK. Cato EP. Moore WEC. Anaerobic laboratory manual. 4th ed. Blacksburg, Virginia: Virginia Polytechnic Institute and State University, 1977.

9 Chang TW, Lauermann M, Bartlett JG. Cytotoxicity assay in antibiotic-associated colitis. $J$ Infect Dis 1979:140:765-70.

${ }^{10}$ Hafiz S, McEntegart MG, Morton RS, Waitkins SA. Clostridium difficile in the urogenital tract of males and females. Lancet 1975;i:420-1.

"Richardson SA, Alcock PA, Gray J. C. difficile and its toxin in healthy neonates. Br Med J 1983;ii:878.

12 Borriello SP, Honour P. Presence of C. difficile and faccal cytotoxin amongst household pets. European Journal of Chemotherapy and Antibiotics 1982:2:129-31.

${ }^{13}$ Mulligan ME, Rolfe RD, Finegold SM, George WL. Contamination of a hospital environment by C. difficilc. Current Microbiology 1979;3:173-5.

${ }^{14} \mathrm{Kim} \mathrm{KH}$, Fekety R, Batts DH, et al. Isolation of $C$ difficile from the environment and contacts of patients with antibioticassociated colitis. $J$ Infect Dis 1981;143:42-5.

15 Pierce PF, Wilson R, Silva J, et al. Antibiotic-associated pseudomembranous colitis: an epidemiologic investigation of a cluster of cases. $J$ Infect Dis 1982;145:269-74.

${ }^{16}$ Larson HE, Barclay FE, Honour P, Hill ID. Epidemiology of Clostridium difficile in infants. $J$ Infect Dis 1982:146:727-33.

17 Cashore WJ, Peter G, Lavermann M, Stonestreet BS, Oh W. Clostridial colonisation and clostridial toxin in neonatal necrotising enterocolitis. J Pediatr 1981;98:308.

${ }^{18}$ Chang TW, Areson P. Neonatal necrotising enterocolitis: absence of bacterial toxins. $N$ Engl $J$ Med 1978;299:424-5.

19 Stoll BJ, Nahmias AJ, Wickliffe C. Brann AW, Dowell VR, Whaley DN. Bacterial toxin and neonatal necrotising enterocolitis. J Pediatr 1980;96:114.

${ }^{20}$ Bartlett JG, Taylor NS, Chang TW, Dzink J. Clinical and laboratory observations in C. difficile colitis. Am J Clin Nutr 1980;33:2521-6.

${ }^{21}$ Lishman AH, Al-Jumaili IJ, Record CO. Spectrum of antibiotic-associated diarrhoea. Gut 1981;22:34-7.

${ }^{22}$ Lyerly DM, Lockwood DE, Richardson SH, Wilkins TD. Biological activities of toxins $\mathrm{A}$ and $\mathrm{B}$ of $\mathrm{C}$. difficile. Infect Immun 1982;35:1147-50.

${ }^{23}$ Stark PL, Lee A, Parsonage BD. Colonization of the large bowel by $\mathrm{C}$. difficile in healthy infants: quantitative study. Infect Immun 1982:35:895-9.

${ }^{24}$ Richardson SA, Brookfield DSK, French TA, Gray J. Pseudomembranous colitis in a 5 week-old infant. $B r$ Med $J$ $1981 ;$ ii: 1510.

${ }^{25}$ Donta ST, Stuppy MS, Myers MG. Neonatal antibioticassociated colitis. Am J Dis Child 1981;135:181-2.

26 Holst E, Helin I, Mardh P-A. Recovery of C. difficile from children. Scand J Infect Dis 1981;13:41-5.

${ }^{27}$ Snyder ML. The normal faecal flora of infants between 2 weeks and one year of age. J Infect Dis 1940;66:1-16.

28 Viscidi RP, Bartlett JG. Antibiotic-associated PMC in children. Pediatrics 1981;67:381-6.

29 Randolph MF, Morris KE. Clindamycin-associated colitis in children: a prospective study and negative report. Clin Pediatr (Phila) 1978;16:722-5.

Correspondence to $\mathrm{Dr}$ R P Bolton, Lecturer in Medicine, University Department of Medicine, St James's Hospital, Leeds LS9 7TF.

Received 6 February 1984 